\title{
CRISIS POSBÉLICA Y MERCADOS DE TRIGO. EL RETORNO DEL PROHIBICIONISMO, 1910-1923
}

\author{
Enrique Montañés Primicia \\ Universidad de CÁdiz
}

\section{RESUMEN}

Durante el periodo de entreguerras la cuestión triguera se convirtió en una de las manifestaciones destacadas de las tensiones entre las zonas agrícolas y urbanas. La primera guerra mundial alteró de forma profunda el funcionamiento del mercado internacional de trigo y tuvo indudables repercusiones sobre el mercado español. Al tradicional instrumento de regulación del mercado nacional, el arancel, se añadieron numerosas medidas intervencionistas que intentaron limitar el papel de la oferta y la demanda. Este trabajo estudia las alteraciones de los mercados, el creciente papel intervencionista del Estado, y las encontradas demandas de agricultores y grupos de consumidores urbanos que, en un contexto internacional de progresivas restricciones al comercio exterior, desencadenaron un extenso conflicto redistributivo de indiscutible impacto sobre el conjunto de la economía española.

PALABRAS CLAVE: Mercados de trigo, aranceles, grupos de presión, regulación estatal, proteccionismo.

\section{ABSTRACT}

The fluctuations of the wheat markets in the interwar period caused important conflicts between producers and urban consumers. This paper analyses the changes in the international wheat markets and its impact in the Spanish wheat market. Through 
the study of the government documents, informs of the economic agents, and series of wheat prices and production, this paper analyses the evolution of supply and demand. The distortion of the markets since 1914 generated a conflict situation between the interior surplus regions and the littoral deficit regions, and induced an increasing intervention of the governments. Like in other European countries, Spanish cereal farmers got protectionist measures in order to reduce the damaging trends in the world market of the detriment of littoral urban consumers.

KEY WORDS: Wheat markets, tariffs, protectionism, pressure groups, state regulations.

El objetivo de este trabajo es analizar las condiciones y factores que determinaron el regreso de la prohibición de importar trigo en España en 1922. La perspectiva elegida es la de contrastar la creciente regulación estatal con las demandas de agricultores y consumidores urbanos en las diferentes coyunturas que experimentaron los mercados. Durante este periodo se observa que los grupos de productores y consumidores recurrieron a la movilización social y política para intentar modificar las condiciones del mercado triguero con el objetivo de conseguir una mejora de sus rentas.

Se analiza, en primer lugar, la estructura del mercado triguero en España antes de la primera guerra mundial. Se determinan las regiones productoras y las regiones consumidoras siguiendo la pauta que en su día señalara Perpiñá y Grau ${ }^{1}$. Se valora el papel del arancel como principal instrumento para regular los precios del mercado nacional y su alcance sobre la producción foránea. Posteriormente, se consideran las alteraciones que sufrieron los mercados durante la guerra mundial y tras su finalización. Sobre esta dinámica de los mercados se estudia el amplio conjunto de medidas intervencionistas de los gobiernos españoles y sus resultados. Se subraya especialmente el contexto en el que se produjo el retorno de la prohibición de importar trigo en 1922. Se considera como una de las múltiples reacciones que surgieron contra el funcionamiento competitivo de los mercados en el contexto de una política económica nacionalista más amplia².

El artículo muestra que los grupos de interés trigueros protagonizaron una movilización constante que, apoyada en la inestabilidad de los mercados y en la crisis política del periodo, consiguió establecer una regulación arancelaria muy favorable que les permitió obtener una significativa transferencia de renta manteniendo la misma estructura de los derechos de propiedad de la tierra.

\section{EL MERCADO DE TRIGO EN TORNO A 1914}

En el periodo entre 1900 y 1913 el mercado internacional del trigo conoció una indudable etapa de expansión. El aumento del consumo incentivó el crecimiento de las

1 PERPIÑÁ y GRAU, Román: De economía hispana, infraestructura, historia, Barcelona, Ariel, 1972, p. 47.

2 COMÍN COMÍN, Francisco: "Hacia la economía dirigida y protegida, a pesar de las críticas de los economistas (1907-1935)", en E. Fuentes Quintana (Dir.), Economía y economistas españoles, Barcelona, Galaxia Gutenberg, 2001, v. 6, pp. 941-989. 
superficies cultivadas y de la producción. Los grandes países exportadores de ultramar, Estados Unidos, Canadá, Argentina y Australia, incrementaron de forma notable sus exportaciones hacia Europa: de 7,6 a 12,9 millones de toneladas ${ }^{3}$. Casi todos los países europeos recurrieron a las importaciones en mayor o menor medida, salvo Rusia y los países del Danubio que eran netamente exportadores. El principal instrumento de intervención de los gobiernos de los países importadores para regular el mercado nacional fue el arancel.

España pertenecía al grupo de países que necesitaba importar trigo para completar sus necesidades, pero la importación estaba constreñida por la existencia de un alto arancel. A pesar de la necesidad de recurrir a las importaciones, el cultivo del trigo seguía siendo la principal producción del sector agrario español. El cultivo asociado de cereales y leguminosas representaba entre 1909 y 1913 cerca del 42\% del valor de la producción total agraria, y sólo el trigo alcanzaba el $21 \%{ }^{4}$. Además, si tenemos en cuenta que el sector agrario aportaba el $31 \%$ del PIB en aquel periodo, la importancia decisiva del trigo era indiscutible ${ }^{5}$.

El mercado español de trigo estaba claramente conformado por la existencia permanente de unas regiones productoras con excedentes y de unas regiones consumidoras con elevados déficit. Como ya señaló Perpiñá y Grau ${ }^{6}$, las regiones agrícolas del interior encauzaban sus excedentes hacia las zonas litorales con déficit estructurales ${ }^{7}$. Castilla y León, con un $48 \%$ de la superficie cultivada, destacaba por su determinante protagonismo en el cultivo del trigo, aunque alcanzaba una menor productividad por hectárea. Junto con la región del valle del Ebro y las provincias de Extremadura y del interior de Andalucía sumaban el $83 \%$ de la superficie cultivada. Todas ellas atendían los importantes déficit de la provincia de Madrid, del litoral andaluz (con un balance negativo a pesar de su preferente dedicación agraria), del litoral mediterráneo o septentrional.

Pero la comercialización de los excedentes de las regiones agrícolas del interior en los mercados del litoral necesitaba el imprescindible concurso de un arancel protector. Desde que los trigos de ultramar incrementaran su presencia en los mercados europeos en las últimas décadas del siglo XIX, los precios tendieron a la baja y los trigos del interior tuvieron problemas para mantener su presencia en los mercados litorales. El aumento del derecho arancelario sobre los trigos extranjeros se convirtió en uno de los medios principales para mantener la competitividad de los trigos del interior en los mercados urbanos de las zonas litorales ${ }^{8}$. El arancel Cánovas y el arancel de 1906

3 BOTELLA FUSTER, Enrique: "El mercado mundial del trigo", Revista de Estudios Agrosociales, 9, 1954, p. 33.

4 SIMPSON, James: "La producción y la productividad agraria españolas 1890-1936", Revista Historia Económica, Año XII, 1994, Invierno, $\mathrm{n}^{\circ}$ 1, p. 67.

5 PRADOS DE LA ESCOSURA, Leandro: El progreso económico de España (1850-2000), Bilbao, Fundación BBVA, 2003, p. 203. En consecuencia, la producción triguera, valorada a partir de los precios del mercado nacional, vendría a suponer el $8 \%$ del PIB calculado por Prados de la Escosura.

6 PERPIÑÁ y GRAU, Román: op. cit., p. 47.

7 La reconstrucción de la estructura del mercado de trigo en España en el apéndice I.

8 Un análisis histórico del mercado triguero en G. E. H. R.: "Los precios del trigo y de la cebada, 1874-1906", en Ramón Garrabou y Jesús Sanz (eds.), Historia agraria de la España contemporánea, vol. 2. Expansión y crisis (1850-1900), Barcelona, Crítica, 1985, pp. 321-368. La producción triguera a finales del siglo XIX en BARQUÍN GIL, Rafael: "La producción de trigo en España en el último tercio del siglo XIX. Una comparación internacional", Revista de Historia Económica, Año XX, 2002, Invierno, nº 1, pp. 11-38. 
consagraron la protección preferente hacia el trigo, que se convirtió en uno de los rasgos más destacados de la política comercial ${ }^{9}$.

La significativa protección que disfrutaba la producción triguera habría permitido también un crecimiento de la superficie cultivada del 5\% entre 1901-1904 y 1910-1914. Aunque la producción apenas se incrementó en un 3\%, por lo que los rendimientos por hectárea tendieron a disminuir, hasta un $2 \%$. Estos pobres resultados obligaron a recurrir a las importaciones, encarecidas apreciablemente por el arancel vigente.

Las cifras que he estimado para el consumo español de trigo entre 1909 y 1913 nos señalan la existencia de un déficit anual de cerca de 875.817 quintales métricos, los correspondientes a la Península y Baleares indicados en el apéndice I, más los necesarios para abastecer a las Canarias y los enclaves africanos. Este déficit global representó algo más del $2 \%$ del consumo total. Las importaciones ${ }^{10}$ fueron una necesidad ineludible y, de acuerdo con las cifras oficiales del comercio exterior español, alcanzaron 1.215.874 quintales métricos de promedio anual. Aunque esta cantidad fue significativamente menor, hasta un $67 \%$, que la señalada por las importaciones en el quinquenio precedente entre 1904 y 1908. El origen de las importaciones durante este periodo se situó de forma preferente en Rusia, Argentina o Rumanía ${ }^{11}$. Según las mismas fuentes oficiales, el arancel efectivamente cobrado fue de 8 pesetas el quintal métrico, que garantizó una protección efectiva de cerca del $36 \%$ sobre los precios internacionales del trigo, es decir, los que regían en el mercado británico.

El constante incremento de las exportaciones de trigo desde los países de ultramar hacia Europa permitió una cierta estabilidad de los precios internacionales. Gran Bretaña importó en el periodo 1909-1913 un promedio anual de más de 52 millones de

9 La bibliografía sobre la política arancelaria y sus efectos en este periodo es muy amplia: SERRANO SANZ, José María: El viraje proteccionista en la Restauración, 1875-1895, Madrid, Siglo XXI, 1987; SERRANO SANZ, José María: "El proteccionismo y el desarrollo económico en la Restauración. Reflexiones para un debate", Revista de Historia Económica, año VII, 1989, nº 1, pp. 133-156; SABATÉ SORT, Marcela: El proteccionismo legitimado. Política arancelaria española a comienzos de siglo, Madrid, Civitas, 1996; GALLEGO, Domingo y PINILLA, Vicente: "Del librecambio matizado al proteccionismo selectivo: el comercio exterior de productos agrarios y alimentos en España entre 1849 y 1935", Revista de Historia Económica, año XIV, 1996, nº 2, pp. 371-420; HERRANZ, Alfonso y TIRADO, Daniel A.: "La restricción exterior al crecimiento económico español (1870-1913)", Revista de Historia Económica, año XIV, 1996, $\mathrm{n}^{\circ}$ 1, pp. 11-49; NADAL, Jordi y SUDRIÁ, Carles: (1993), "La controversia en torno al atraso económico español en la segunda mitad del siglo XIX (1860-1913)", Revista de Historia Industrial, no 3, 1993, pp. 199224; PALAFOX, Jordi: Atraso económico y democracia. La Segunda República y la economía española, 1892-1936, Barcelona, Crítica, 1991; TIRADO, Daniel: "Protección arancelaria y evolución de la economía española durante la Restauración: un ensayo interpretativo", Revista de Historia Industrial, n 9, 1996, pp. 5381; FRAILE BALBÍN, Pedro: Industrialización y grupos de presión. La economía política de la protección en España 1900-1950, Madrid, Alianza, 1991; GALLEGO MARTÍNEZ, Domingo: "De los limitados efectos de la política arancelaria sobre las orientaciones productivas del sector agrario español (1869-1914)", en C. Sudrià y D. A. Tirado (Eds.), Peseta y protección. Comercio exterior, moneda y crecimiento económico en la España de la Restauración, Barcelona, Universitat de Barcelona, 2001, pp. 45-70; PARDOS MARTÍNEZ, Eva: La incidencia de la protección arancelaria en los mercados españoles (1870-1913), Madrid, Banco de España, 1998; TENA, Antonio: "Un nuevo perfil del proteccionismo español durante la Restauración, 18751930”, Revista de Historia Económica, 17, 1999, no 3, pp. 579-621; TENA, Antonio: “¿Por qué fue España un país con alta protección industrial? Evidencias desde la protección efectiva 1870-1930", Documento de Trabajo 02-03, Departamento de Historia Económica e Instituciones, Universidad Carlos III, Madrid, 2001. 10 He resumido la evolución de la producción, de la importación y de las existencias anuales de trigo en el apéndice II.

11 Durante el bienio en el que se efectuaron las importaciones más cuantiosas, entre 1905 y 1906, el trigo importado provino principalmente de Rusia (40\%), Argentina (15\%) y Rumanía (14\%), en COMISION PARA EL ESTUDIO DE LA PRODUCCIÓN Y EL CONSUMO DE TRIGO: Su nombramiento. Actas de las sesiones. Dictamen y apéndices, Madrid, 1909, p. 262. 
quintales métricos ${ }^{12}$, y pudo disfrutar de unos precios inferiores a los existentes en las zonas productoras españolas del interior. Como señaló Flores de Lemus ${ }^{13}$, los precios españoles venían determinados por el arancel vigente. Con una protección efectiva tan alta los precios de Barcelona, representativos de las zonas litorales deficitarias, fueron un cincuenta por ciento más elevados que los británicos. El papel central del arancel para comercializar los excedentes de las zonas del interior en las zonas litorales era indiscutible.

Como ya ha sido suficientemente resaltado, el protector arancel sobre el trigo fue el resultado de la movilización de los intereses agrarios ${ }^{14}$, de su influencia sobre el poder político y de la coincidencia con los intereses industriales en la necesidad de una orientación nacionalista de la política comercial ${ }^{15}$. Los trabajos realizados por la Comisión para el estudio de la producción y consumo del trigo, creada por el ministro de Hacienda en 1907, sintetizan el discurso y las demandas de los grupos de presión agrícolas y nos muestran su capacidad para determinar la política gubernamental ${ }^{16}$. La Comisión estaba integrada por diputados, senadores, funcionarios y representantes de las organizaciones agrarias favorables, la mayoría de ellos, al mantenimiento de un alto arancel protector sobre el trigo.

Las tesis que subyacen en el dictamen que elaboró la Comisión son las mismas que se venían sosteniendo desde los años ochenta del siglo XIX. Proclamaban la necesidad ineludible de mantener una protección eficaz para defender el cultivo del trigo en las grandes extensiones de los secanos de Castilla y del sur. Las dificultades generadas por la falta de lluvias, por los reducidos rendimientos de los suelos, o por la pobreza del pequeño campesino que seguía manteniendo sistemas de cultivo tradicionales, exigían la existencia de un arancel que permitiera al cultivador obtener un precio remunerador. Los agricultores sostenían que la política comercial beneficiaba, sobre todo, a las grandes industrias y consideraban imprescindible conservar el único elemento que beneficiaba al sector: el arancel triguero.

Los intereses agrarios trabajaron con intensidad en el seno de la Comisión para lograr el reconocimiento de un precio remunerador favorable. Como en anteriores ocasiones, la selección y el tratamiento de la información estuvieron muy condicionados por el carácter de las conclusiones que se deseaban alcanzar. El estudio de la enorme diversidad de explotaciones y empresas existentes, determinadas por diferentes factores como la calidad de los suelos, el volumen de precipitaciones, el tamaño de la explotación o los sistemas de cultivo, se simplificaron radicalmente. Dada la enorme importancia del concepto de precio remunerador en la determinación del arancel respecto al trigo, es muy conveniente conocer qué realidades económicas se tomaron como referencia.

12 MITCHELL, Brian R. y DEANE, Phyllis: Abstract of British Historical Statistics, Cambridge, Cambridge University Press, 1962, p. 99.

13 FLORES DE LEMUS, Antonio: "Algunos datos estadísticos sobre el estado actual de la economía española”, Hacienda Pública, nº 42-43, 1976, p. 440.

$14 \mathrm{El}$ peso de los intereses trigueros en la configuración de la política comercial durante el régimen liberal español en MONTAÑÉS, Enrique: Grupos de presión y reformas arancelarias en el régimen liberal, 18201870, Cádiz, Universidad de Cádiz, 2009.

15 El énfasis de la política arancelaria en la protección del trigo en GALLEGO MARTÍNEZ, Domingo: "De los limitados efectos de la política arancelaria...,, p. 53. La rentabilidad de la búsqueda de rentas con políticas de restricción de la oferta en FRAILE BALBÍN, Pedro, op. cit.

16 Sus actuaciones en Comisión para el estudio de la producción y el consumo de trigo, op. cit. 
Aunque aparentemente se tuvieron en cuenta diferentes tamaños de fincas (pequeña, mediana o grande), en realidad todos los casos respondían a un tipo de explotación muy tradicional. Dominaba la rotación trienal con presencia ineludible del barbecho, el abonado orgánico limitado, la ausencia de mecanización (sólo en el caso de la explotación grande para la trilla), un importante peso del gasto salarial (aunque los salarios eran bajos), y pobres rendimientos por hectárea (incluso por debajo de la media de sus respectivas comarcas). Además, la renta de la tierra seguía teniendo una destacada presencia en los gastos anuales: entre el 25 y el $30 \%{ }^{17}$.

La determinación del precio remunerador no fue el resultado de un estudio objetivo y ponderado, sino que fue una auténtica actuación política producto de un consenso entre los diferentes intereses agrícolas. La Comisión creada en 1907 fijó el precio remunerador en 25 pesetas el quintal métrico y siguió defendiendo la necesidad de mantener el arancel en las 8 pesetas el quintal métrico. Como se ha podido apreciar, durante el periodo 1909-1913 el precio de los mercados en las zonas excedentarias superó al llamado precio remunerador gracias al alto arancel aplicado. Hay que resaltar que el precio remunerador era más elevado que el existente en el principal país importador de Europa. Aunque los portavoces de los intereses agrarios defendían que la protección beneficiaba a todo el sector agrícola y a la economía nacional, en realidad se pretendía conservar la estructura tradicional y los derechos de propiedad que subyacían bajo el precio remunerador demandado. Beneficiaba, sobre todo, al propietario absentista porque podía llegar a obtener una rentabilidad muy similar a la que podía alcanzar el cultivador directo, cerca de un 5\%, debido a la tendencia alcista de la renta de la tierra desde el reforzamiento de la protección ${ }^{18}$.

Dada la enorme desigualdad existente en el sector agrario, la protección acababa beneficiando fundamentalmente a los propietarios de los recursos escasos ${ }^{19}$. La propiedad de la tierra era un recurso escaso, aunque existían diferencias regionales apreciables.

Cuadro 1. Patronos y trabajadores en el sector agrícola, 1920

\begin{tabular}{lcccc}
\hline & Patronos & $\%$ & Trabajadores & $\%$ \\
\hline Castilla y León & 333.124 & 32 & 713.732 & 68 \\
Andalucía oriental & 56.936 & 11 & 477.925 & 89 \\
Andalucía occidental & 30.414 & 10 & 289.171 & 90 \\
Extremadura & 27.447 & 10 & 258.374 & 90 \\
Ebro (Navarra, Aragón, Rioja, & 163.649 & 37 & 280.310 & 63 \\
Lérida) & 611.570 & 23 & 2.019 .512 & 77 \\
Total & & & \\
\hline
\end{tabular}

Fuente: Elaboración propia a partir del Censo de Población, 1920.

17 Las características de las explotaciones estudiadas en Ibídem, pp. 375-391.

18 Sobre la evolución de la renta de la tierra en SIMPSON, James: "La crisis agraria de finales del siglo XIX: una reconsideración”, en C. Sudrià y D. Tirado (eds.), Peseta y protección: comercio exterior, moneda y crecimiento económico en la España de la Restauración, Barcelona, Universitat de Barcelona, 2001, p. 103, y ROBLEDO, Ricardo: La renta de la tierra en Castilla la Vieja y León, 1836-1913, Madrid, Banco de España, 1984. La trayectoria ascendente del precio de la tierra en BRINGAS GUTIÉRREZ, Miguel Ángel: La productividad de los factores en la agricultura española (1752-1935), Madrid, 2000, p. 50.

19 ROGOWSKI, Ronald: Commerce and Coalitions. How Trade Affects Domestic Political Alignments, Princeton, 1989. 
En el sur la protección beneficiaba a una minoría muy reducida de la población activa agraria, entre el 10 y el 11\%, mientras que en Castilla-León y la región del Ebro, las principales zonas excedentarias en la producción de trigo, la proporción se ampliaba hasta el $37 \%$ por la presencia de un pequeño campesino con escasos recursos.

Dada la extraordinaria concentración de la propiedad de la tierra, y la amplia extensión de los diferentes tipos de arrendamientos, el grupo de los propietarios absentistas era uno de los principales beneficiarios por el precio remunerador establecido, ya que conseguía una rentabilidad equivalente a la del cultivador. El propietario que arrendaba su tierra estaba sobre todo preocupado por el precio en el mercado interior: cualquier disminución provocaba una reducción de su renta. Sin embargo, el cultivador, tanto el pequeño como el mediano o el grande, no sólo estaba preocupado por el precio, sino por el volumen de la cosecha. Una buena cosecha, aun con precios menores, reducía el coste de la renta de la tierra y podía proporcionar ingresos más elevados. Dependía de su capacidad para vender el producto en el momento adecuado a lo largo del año.

El pequeño cultivador, generalmente endeudado y con escasa capacidad para almacenar su producción, vendía su cosecha inmediatamente y a precios inferiores a los señalados en los mercados regionales. En realidad, los principales mercados de las zonas productoras o de las zonas urbanas consumidoras eran mercados con pocos operadores: grandes propietarios que tenían medios para acumular importantes cantidades, o comerciantes especializados que disponían de suficiente capacidad financiera. Los comerciantes desempeñaban un papel central en la configuración del mercado nacional. Proporcionaban financiación a los pequeños cultivadores, almacenaban el trigo de las sucesivas cosechas, y lo comercializaban de forma gradual a lo largo del año hacia las zonas netamente consumidoras aprovechando las oscilaciones coyunturales de los precios ${ }^{20}$. También los comerciantes necesitaban un alto arancel para asegurar una suficiente rentabilidad a sus especulaciones. En una etapa de cierta estabilidad de los precios en los mercados internacionales el arancel fijo permitía obtener una rentabilidad garantizada.

En consecuencia, la trayectoria histórica del mercado del trigo determinó la consolidación de una amplia coalición de intereses, propietarios, cultivadores y comerciantes, de un ámbito geográfico muy amplio y con un importante poder económico, social y político, que logró que los gobiernos fijaran una elevada protección arancelaria a partir de un llamado precio remunerador, que tomaba como referencia los sistemas de explotación más atrasados ${ }^{21}$. Aunque en la innumerable cantidad de discursos y escritos que se difundieron en la época se reconoció el escaso progreso del sector, incluso se afirmó que poco había cambiado la situación respecto a los años ochenta del siglo XIX, y algunos llegaron a afirmar que había que mejorar la productividad del sector con el abandono de algunas tierras marginales ${ }^{22}$, se mantuvo una constante presión sobre los gobiernos para evitar cualquier alteración del arancel vigente.

20 El funcionamiento de "ese conato de mercado" en CÁNOVAS DEL CASTILLO, Jesús y GAMAZO ABARCA, Juan Antonio: Aspecto económico-arancelario de la producción cereal en España, Madrid, 1915, p. 17.

21 BERNAL, Antonio Miguel: "Resistencias al cambio económico desde el sector agrícola (1880-1931)", en J.

L. García Delgado (Ed.), España entre dos siglos (1875-1931).Continuidad y cambio, Madrid, 1991, p. 151.

22 Algunos caracterizados representantes de los intereses agrarios propugnaban que los agricultores que no pudieran producir el trigo por debajo del precio remunerador, que elevaban hasta 28 pesetas el quintal métrico, debían abandonar el cultivo, en CÁNOVAS DEL CASTILLO, Jesús y GAMAZO ABARCA, Juan Antonio, op. cit., p. 35. 
Al tomar como referencia la estructura de costes de las explotaciones más tradicionales para fijar un alto arancel, los intereses agrícolas pretendían reducir los efectos deflacionistas que transmitían los mercados internacionales para conservar sin cambios una determinada estructura de los derechos de propiedad. Ya antes de 1914, los estímulos que generaba el mercado para impulsar una asignación más eficiente de los recursos estaban muy distorsionados por las políticas de restricción de la oferta que el arancel triguero implicaba. El diferencial de los precios españoles respecto al precio internacional del trigo mostraba una transferencia de renta, que aunque asumida por los grupos industriales en el contexto de una política proteccionista global, no dejaba de generar tensiones y conflictos entre las zonas productoras con excedentes y las ciudades deficitarias del litoral. Éstas preferían recurrir a la importación de trigos más baratos para impulsar su industria harinera, muy afectada por la independencia de las últimas colonias americanas, y reducir el precio de las subsistencias frente a una numerosa clase obrera en proceso de reorganización sindical.

Como han señalado algunos autores ${ }^{23}$, el arancel no era el único responsable del atraso agrícola, ni de la distribución de los usos del suelo. Debemos de tener en cuenta un conjunto más amplio de factores, pero el arancel tenía una incidencia muy destacada en la configuración del mercado nacional. La constante movilización de los intereses agrarios así lo confirma. Si tomamos como referencia las cifras oficiales (memorias, dictámenes, anuarios) que se empleaban para adoptar las regulaciones gubernamentales, la cuantía del arancel podía tener una incidencia muy significativa. Si con un arancel no superior al $10 \%$ se hubiera importado una parte del déficit del litoral, por ejemplo unos cuatro millones de quintales métricos, la contracción de la superficie sembrada de trigo en la zona de Castilla y León, la de menor productividad, hubiera podido llegar hasta el medio millón de hectáreas, cerca de un $27 \%$. Un alto arancel ayudaba a que el coste de oportunidad del trigo siguiera siendo bajo ${ }^{24}$.

Aunque las comparaciones internacionales muestran la escasa competitividad de la producción triguera española ${ }^{25}$, no podemos saber con seguridad si se hubiera producido esa apreciable disminución de la superficie cultivada porque, siempre de acuerdo con las cifras oficiales comúnmente aceptadas, existía un amplio margen para la reducción de los costes de producción. En primer lugar, la renta de la tierra habría tendido a reducirse ${ }^{26}$. Por otro lado, como los rendimientos por hectárea eran más elevados que los reconocidos, y se habían ido introduciendo algunos elementos de innovación tecnológica (mecanización, abonos) ${ }^{27}$, los cultivadores directos no habrían

23 GALLEGO MARTÍNEZ, Domingo: "De los limitados efectos de la política arancelaria..."; SIMPSON, James: "Did tariffs stifle Spanish agriculture before 1936", European Review of Economic History, n 1, 1997, pp. 65-87.

24 La importancia del coste de oportunidad en la elección del cultivo triguero en TORRES, Manuel: El problema triguero y otras cuestiones fundamentales de la Agricultura española, Madrid, CSIC, 1944, p. 49.

25 SIMPSON, James: La agricultura española (1765-1965): la larga siesta, Madrid, Alianza, 1997, p. 173; BRINGAS GUTIÉRREZ, Miguel Angel, op. cit., p. 71.

26 FLORES DE LEMUS, Antonio: "Sobre una dirección fundamental de la producción rural española", Hacienda Pública, $\mathrm{n}^{\circ} 42-43,1976$, p. 483, advirtió que el peso de la renta de la tierra era uno de los elementos destacados que lastraban la competitividad de los trigos del interior. CASCÓN, J.: "El cultivo del trigo en España”, Información Comercial Española, febrero, 1965, p. 161, señaló el obstáculo de los sistemas de arrendamiento a corto plazo.

27 Desde 1905 se habría ampliado el uso de fertilizantes y el empleo de maquinaria, SIMPSON, James: "La crisis agraria de finales del siglo...,", p. 108. 
visto mermada considerablemente su rentabilidad. Sin embargo, para aquellos que sólo dependían del precio y no de las cantidades cosechadas, los rentistas y los comerciantes, cualquier modificación del arancel a la baja implicaba una alteración de su posición en los mercados y una menor remuneración a sus prácticas tradicionales.

\section{LAS ALTERACIONES DE LA GUERRA}

Con el desencadenamiento de la guerra europea en 1914 la situación de los mercados del trigo se vio profundamente alterada. Entre 1914 y 1919 la producción de los países europeos sufrió un notable recorte. La producción en los países exportadores de Europa retrocedió un $30 \%$. Rusia y el resto de los países del Danubio, que con anterioridad exportaban más de 6 millones de toneladas, dejaron de contribuir al mercado internacional ${ }^{28}$. Asimismo, la producción de los países importadores se redujo un $18 \%$. Esta contracción de la oferta de trigo intentó ser compensada con un aumento de la producción por parte de los países exportadores de ultramar, un $18 \%$, y por los exportadores del norte de África, un 3\%. En el conjunto mundial, la oferta de trigo sólo retrocedió en un 3\%. Pero la enorme extensión del conflicto bélico encareció de forma considerable los gastos de transporte, y aparecieron problemas de abastecimiento en determinadas zonas de Europa. El crecimiento de los precios, tanto en las zonas productoras como en los países importadores de Europa, fue generalizado y también se alimentó de las tendencias inflacionistas generales.

En España, durante ese mismo periodo entre 1914 y 1919, se aumentó la superficie cultivada un $8 \%$, sobre el promedio entre 1905 y 1913, y la producción un $11 \%$, lo que permitió una leve mejoría de la productividad del 3\%. El aumento de los precios en los mercados internacionales actuó como un eficaz estímulo. A pesar de ese incremento de la oferta española de trigo, las importaciones crecieron un $11 \%$ gracias a la reducción drástica del arancel, entre 1915 y 1916, y a su eliminación total entre 1917 y 1921. Las importaciones llegaron a representar el $7 \%$ del consumo total español. El crecimiento de los precios en los mercados internacionales inclinó a los gobernantes españoles hacia una política intervencionista para intentar frenar el alza de los precios y reducir la conflictividad social en los núcleos urbanos. Recurrieron a leyes excepcionales para reglamentar el mercado, establecieron precios de tasa para el trigo, y trataron de regular las transacciones del mercado.

La pobre cosecha de 1914 generó el temor a una escasez generalizada, y propició una importación muy señalada de trigo de más de cuatro millones de quintales métricos con un arancel que no llegó al dos por ciento. A pesar de ese volumen desconocido de importaciones, la demanda no pudo atenderse y los precios subieron tanto en la zona productora del interior como en el litoral. En los dos años siguientes se obtuvieron buenas cosechas, pero las autoridades gubernamentales siguieron facilitando la importación con ese mínimo arancel ${ }^{29}$. A pesar de las continuas protestas de los grupos de presión agrícolas, los gobiernos prefirieron asegurar el abastecimiento para las poblaciones del litoral aún a costa de acumular importantes reservas.

28 BOTELLA FUSTER, Enrique: op. cit., p. 33; MALENBAUM, Wilfred: The World Wheat Economy, 1885-1939, Cambridge, MA, Harvard University Press, 1953, pp. 236-241.

29 Las disposiciones arancelarias sobre el trigo en esos años y las presiones de los intereses agrícolas en ROLDÁN, Santiago, GARCÍA DELGADO, José Luis y MUÑ́́Z, Juan: La formación de la sociedad capitalista en España 1914-1920, Madrid, 1973, pp. 145-172. 
En 1916, tras constatar las limitaciones de las reducciones arancelarias para frenar el crecimiento de los precios, el Gobierno estableció un régimen de tasas para la venta del trigo. Los precios máximos que se fueron fijando sucesivamente, 36 pesetas el quintal para 1916, 44 pesetas para 1918, o 48 pesetas para 1919, fueron superados en los mercados de las zonas productoras. Es evidente que el Estado carecía de una organización administrativa adecuada para vigilar todas las transacciones. Pero cuando se propuso una actuación más decidida para hacer cumplir la tasa surgió el problema del desabastecimiento. El proceso inflacionario desatado desde 1914 inclinó a los agricultores a intentar conseguir unos precios que les permitieran obtener un incremento real de sus ingresos. Apoyados en el alza de los precios de los transportes marítimos ${ }^{30}$ y en las alteraciones de los mercados internacionales, los grupos de presión agrícolas defendieron durante este periodo el libre funcionamiento de los mercados al margen de las intervenciones gubernamentales ${ }^{31}$.

La menor afluencia de importaciones en 1917 y 1918 y la pobre cosecha de 1919 provocaron una reducción de las existencias que siguió impulsando el crecimiento de los precios del trigo por encima del índice general de precios. Esta situación de los mercados hizo inviable la política gubernamental de tasas. Se generalizaron situaciones de escasez en numerosas zonas como nos indican los balances negativos de 1918 y 1919. En algunos puntos, incluso productores, se reprodujeron escenas del siglo anterior: robos masivos en cortijos, bloqueo del transporte del trigo, asaltos a panaderías, o motines de subsistencias. Se alcanzaron los máximos niveles en los precios del trigo en el interior y en el litoral y, al mismo tiempo, la conflictividad social se incrementó notablemente.

El fracaso del régimen de tasas, que contrastaba con el crecimiento de los ingresos de propietarios, cultivadores y comerciantes, promovió la extensión de la movilización sindical ante el deterioro del nivel de vida de las clases trabajadoras. Ésta llegó a ser tan intensa que supuso una creciente amenaza política al régimen de la Restauración. Los gobiernos intentaron paliar la inoperancia de las tasas con medidas intervencionistas más estrictas. Desde 1918 se ensayó la regulación de las transacciones más importantes de trigos y harinas: se obligó a la sindicación de los compradores, se contempló el reparto proporcional de trigo entre las harineras, y se confirmó la obligatoriedad de los precios de tasa. Esta centralización de las operaciones de compra y venta, que debían ser estrechamente vigiladas por las autoridades provinciales, tampoco llegó a ser una realidad por la reiterada incapacidad administrativa del Estado ${ }^{32}$.

En definitiva, en el periodo entre 1914 y 1919 se produjo una notable alteración de los mercados trigueros con respecto a la situación que venían disfrutando desde comienzos de siglo. La reducción de la oferta, el crecimiento de los precios de los transportes y el proceso inflacionario general provocaron un continuo crecimiento de los precios. A pesar de numerosas vacilaciones y medidas contradictorias, las autoridades terminaron

$30 \mathrm{El}$ aumento de los fletes de cereales desde Buenos Aires a Cádiz y Barcelona en Ibídem, p. 149.

31 El régimen de tasas sobre el trigo y las demandas de los agricultores en HERMIDA REVILLAS, Carlos: Economía agraria y agitaciones campesinas en Castilla la Vieja y León: 1900-1936, Madrid, Universidad Complutense, 1989, pp. 95-100.

32 La legislación reguladora del mercado de trigo y su efectividad en Ibídem, p. 96. La defensa de la libertad de mercado por los agricultores durante el periodo bélico en MONTOJO SUREDA, Jorge: La política española sobre trigos y harinas (años 1900-1945), Madrid, 1945, p. 23. 
por facilitar las importaciones y restringir las exportaciones ante unos precios interiores en constante aumento, y ante el temor de una creciente conflictividad social. Existieron razones objetivas para esa actuación. Por un lado, la movilización sindical en Barcelona creció de forma muy notable, y por otro, el precio del trigo en el litoral, a pesar de las importaciones, siguió siendo más elevado en algunos momentos que el registrado en el mercado inglés. Asimismo, en otras regiones, como Andalucía del interior y la del litoral, los conflictos sociales en el campo se radicalizaron y se extendieron y, al mismo tiempo, se originaron en determinados momentos situaciones de escasez y desabastecimiento que impulsaron subidas adicionales de precios.

Las intervenciones sobre el arancel demostraron su eficacia para garantizar el abastecimiento del mercado español en los primeros años. Su eliminación facilitó las importaciones, pero cuando éstas se redujeron los precios crecieron con rapidez. $\mathrm{Si}$ observamos este periodo en su conjunto, los propietarios y agricultores pudieron disfrutar de una importante etapa de acumulación ${ }^{33}$. Los precios del trigo, tanto en el interior como en el litoral, crecieron por encima del conjunto de los precios, de los salarios agrícolas o de los salarios industriales. Ello fue posible a pesar de haberse liberalizado la importación de trigo, pero gracias a la profunda alteración de los mercados internacionales desencadenada por el conflicto bélico europeo.

\section{LA CRISIS TRIGUERA DE LA POSGUERRA. EL FIN DE LA EXCEPCIONALIDAD}

Después de seis años de continuos incrementos de los precios del trigo en el mercado norteamericano, en 1920 se produjo un descenso del $24 \%$ respecto al año precedente $^{34}$. Esta caída continuó en los años siguientes. Entre 1920 y 1924 el recorte fue del $43 \%$ respecto al periodo de precios máximos de 1918-1919. Esta tendencia señalaba la propensión de los mercados a volver a las condiciones previas al conflicto bélico. Pero ese retorno no fue un proceso automático e inmediato. En un contexto de profundas alteraciones monetarias, los precios del trigo siguieron siendo un $43 \%$ más elevados que en el periodo entre 1910 y 1913.

Durante esa etapa de posguerra, la oferta mundial de trigo no tuvo la misma composición que en la etapa prebélica. Aunque los países exportadores de ultramar continuaron incrementando la superficie cultivada y la producción hasta el $31 \%$ del nivel de preguerra, los exportadores europeos retrocedieron en superficie cultivada y apenas alcanzaron un $74 \%$ de la producción previa. La URSS dejó de exportar por completo. Por otro lado, los importadores europeos tampoco lograron una recuperación íntegra: apenas alcanzaron un $90 \%$ superficie cultivada y un $86 \%$ de la producción anterior a la guerra ${ }^{35}$. Globalmente, la producción mundial se incrementó un 5\% respecto al nivel de preguerra, lo cual permitió consolidar esa tendencia claramente descendente de los precios.

En España, los agricultores, estimulados por los altos precios desde 1914, siguieron ampliando la superficie cultivada, pero la producción creció en menor medida debido al

33 La coyuntura alcista del periodo bélico facilitó una etapa de capitalización en el sector, TORRES, Manuel: op. cit., p. 17. 
estancamiento de los rendimientos por hectárea. Los problemas de desabastecimiento, y la intensa conflictividad social experimentada entre 1917 y 1919, inclinaron a los gobiernos a incrementar las medidas intervencionistas sobre el mercado. En 1920 se aprobaron nuevas disposiciones que obligaron a los agricultores a declarar su producción, y que reforzaron el control estatal de las transacciones con una fiscalización más rigurosa sobre los comerciantes y las harineras. Pero la oposición de los intereses agrícolas, que demandaban la vuelta a la libertad de mercado, bloqueó su efectiva puesta en práctica. Finalmente, en septiembre de 1920 se restableció la libertad de circulación y contratación de trigo ${ }^{36}$.

Si los intentos gubernamentales de imponer tasas obligatorias y de fiscalizar las transacciones no fueron muy eficaces, las facilidades otorgadas a la importación sí que tuvieron una mayor incidencia. Las importaciones de trigo, libres de cualquier arancel, se situaron en torno a los cinco millones de quintales métricos anuales en 1920 y 1921. Como las cosechas españolas no fueron malas en estos años, las reservas pudieron aumentar ostensiblemente. De esta manera, los precios bajaron de forma apreciable en 1921, sobre todo en el litoral deficitario.

La liberalización del comercio exterior del trigo permitió trasladar al mercado interior la tendencia descendente de los precios en los mercados internacionales. Pero este proceso fue entendido por los agricultores y propietarios como una agresión a sus intereses. En 1922 el precio del trigo en las zonas productoras y en el litoral continuó reduciéndose e, incluso, fue muy similar, mientras afluían las importaciones en los primeros meses del año. Ya en 1921, el precio del trigo en el litoral se situó por debajo del crecimiento general de los precios, mientras que los salarios agrícolas e industriales crecieron por encima. En 1922 los precios del trigo de las zonas productoras del interior y los del litoral disminuyeron más rápidamente que el índice general de precios, mientras que los salarios siguieron ganando poder adquisitivo ${ }^{37}$.

Las tensiones entre interior y periferia se incrementaron por la evolución del mercado español entre 1910 y 1920. De acuerdo con la reconstrucción del mercado expuesta en el apéndice I, Castilla y Aragón aumentaron la superficie cultivada y los excedentes, mientras que el sur redujo la superficie y pasó a una situación deficitaria por una brusca caída de la productividad generada, entre otros factores, por la intensa conflictividad social. Por otro lado, el litoral incrementó ligeramente su déficit. El retorno a la normalidad, con el descenso de los precios internacionales, cuestionó la viabilidad de esa ampliación de la superficie cultivada. El interior había aumentado su superávit en un $43 \%$ y la superficie cultivada en un $13 \%$. A pesar de estos excedentes, el déficit global del mercado español creció un 19\%, aunque siguió representando una pequeña cantidad respecto al consumo total $(2 \%)$. Pero el problema central estaba en si los consumidores del litoral estaban dispuestos a adquirir, tras un periodo de libre importación, unos excedentes del interior más caros que los trigos más baratos que ofrecía el mercado internacional.

36 La evolución de la legislación sobre el trigo y las demandas de los intereses agrícolas en HERMIDA REVILLAS, Carlos: op. cit., p. 99.

37 La trayectoria de los salarios en este periodo en CARRERAS, Albert y TAFUNELL, Xavier (Coords.): Estadísticas históricas de España, Bilbao, 2005, pp. 1.221-1.224. La disminución de los ingresos de los agricultores desde 1922 en FLORES DE LEMUS, Antonio: "Sobre una dirección fundamental...", p. 469. 


\section{LA CAMPAÑA DE LOS GRUPOS DE PRESIÓN TRIGUEROS. EL RETORNO AL PROHIBICIONISMO}

Esos hechos objetivos están detrás de la campaña de los agricultores y propietarios en demanda de medidas proteccionistas que redujeran el deterioro de sus rentas. Mientras que durante 1920, en el momento de máximo crecimiento de los precios, demandaron el fin del intervencionismo estatal y el establecimiento de la libertad de mercado, desde 1921, con el incremento de las importaciones y el comienzo del descenso de precios tras siete años de alza ininterrumpida, exigieron el restablecimiento de las barreras arancelarias. Ya desde 1920 los grupos de interés agrícolas, con motivo de la revisión arancelaria, desarrollaron una amplia campaña denunciando el favoritismo oficial que disfrutaba la industria y el abandono que sufría la agricultura. Pero en 1921 la movilización de las organizaciones agrarias se intensificó ante lo que consideraron un tratamiento muy desigual en el arancel respecto a la industria en una coyuntura de rápido descenso de precios $^{38}$.

La movilización de los trigueros consiguió que el gobierno conservador presidido por Manuel Allendesalazar aprobara en abril de 1921 una nueva regulación favorable a sus intereses. En la real orden de 6 de abril ${ }^{39}$, firmada por el ministro de Fomento Manuel Argüelles, no sólo se restableció el arancel sino que también se adoptaron otras medidas restrictivas. En primer lugar, se limitó el empleo del trigo extranjero en las fábricas de harina: el trigo nacional debía suponer como mínimo el 50\% de la materia prima molturada. Además, para evitar el exceso de oferta en el mercado, el Gobierno se comprometió a no vender la importante cantidad de trigo importado de su propiedad que se encontraba almacenado en el litoral para prevenir las crisis de escasez. Es indudable que estas medidas querían frenar la caída de los precios del trigo, de acuerdo con las demandas de los agricultores, pero su efectividad fue muy limitada.

Aunque el Estado renunciara a comercializar las importantes cantidades de trigo importado almacenado, se calculó que poseía más de un millón de quintales métricos ${ }^{40}$, el exceso de oferta no era fácil de eliminar porque las existencias privadas también debían ser muy altas. Como se puede apreciar en el cuadro del apéndice II, que trata de reconstruir la trayectoria del mercado triguero, el excedente generado a lo largo de 1921 podía superar los cinco millones de quintales métricos. La cosecha nacional de 1921 fue muy buena, una de las más elevadas del periodo, pero el trigo importado también alcanzó una cifra excepcional. En consecuencia, las existencias del sector privado también tuvieron que ser muy considerables. Ante la irremediable vuelta a la normalidad del mercado triguero internacional, y la consiguiente caída de precios, los tenedores privados de trigo pudieron tender a liquidar sus stocks, acumulados con

\footnotetext{
38 La movilización de las organizaciones agrarias y sus objetivos en HERMIDA REVILLAS, Carlos: op. cit., pp. 102-117; REY REGUILLO, Fernando: Propietarios y patronos. La política de las organizaciones económicas en la España de la Restauración (1914-1923), Madrid, Ministerio de Trabajo y Seguridad Social, 1992, pp. 230-250; MARTORELL, Miguel: El santo temor al déficit. Política y Hacienda en la Restauración, Madrid, Alianza, 2000, p. 287.

39 Gaceta de Madrid, 7-4-1921, n 97, pp. 97s.

40 Datos proporcionados por el diputado socialista Indalecio Prieto, Diario de Sesiones de Cortes, Congreso de los Diputados (DSC-CD), 7-4-1921, pp. 1.154.
} 
anterioridad y comprados a precios superiores, para tratar de limitar las pérdidas y poder adquirir nuevas existencias a precios inferiores. Esta tendencia de los operadores privados explica el irrefrenable descenso de los precios a pesar de las medidas gubernamentales adoptadas.

La renuncia del Estado a vender sus stocks y el resto de las medidas restrictivas de la oferta, dispuestas en la real orden de 6 abril, facilitó al sector privado la venta más o menos ordenada de sus excedentes y pudo limitar el descenso de precios. Esta nueva regulación del mercado pretendía beneficiar claramente a los agricultores y comerciantes de trigo del interior, dejando en segundo plano el interés de las ciudades deficitarias del litoral por alcanzar una rápida disminución de los precios del trigo. Además, el Estado sufrió una pérdida económica considerable al renunciar a la venta de un trigo comprado a altos precios y que, irremediablemente, acabaría por deteriorarse debido a un largo y precario almacenamiento.

En aquel momento, ya hubo voces que criticaron abiertamente la nueva regulación adoptada por el gobierno conservador. El diputado socialista Prieto, representante de los sectores obreros de las ciudades del litoral deficitario, se escandalizó en el Congreso por esa regulación que pretendía de forma tan descarada evitar la reducción de los precios del trigo. Prieto calificó de inadmisible esa actuación gubernamental que pretendía mantener unos precios del trigo artificiales mientras, al mismo tiempo, se presionaba a los sectores obreros para que redujeran sus salarios ${ }^{41}$.

Pero con el restablecimiento del arancel no cesó la campaña de los grupos agrarios a favor de medidas proteccionistas. Todo lo contrario, se incrementó cuando el nuevo gobierno de concentración presidido por Maura, constituido en agosto de 1921 y del que formaba parte Cambó como ministro de Hacienda, decidió afrontar una reforma arancelaria. Los grupos de presión agrícolas criticaron abiertamente el proyecto de reforma arancelaria propuesto por Cambó. Proclamaron que, sobre todo, era un proyecto que beneficiaba a los industriales siderúrgicos y textiles por la amplia protección contemplada a sus productos, que encarecía el carbón, la maquinaria y los abonos químicos empleados por los agricultores, mientras que la protección para el trigo, un arancel de 10 pesetas por quintal, era muy insuficiente ${ }^{42}$.

Cambó intentó superar el rechazo a su proyecto negociando con los diputados agrarios, muy necesarios para superar el trámite parlamentario, algunas compensaciones. La más importante fue la aprobación de un decreto en noviembre de 1921 por el que se prohibió de forma temporal la importación de trigo extranjero con el objetivo de frenar la caída de los precios ${ }^{43}$. A pesar de esta concesión, la campaña de los grupos de presión agrícolas en contra del proyecto arancelario de Cambó no se frenó en los primeros meses de 1922. La Asociación de Agricultores de España calificó el proyecto de Cambó de "perturbador” y "suicida" ${ }^{4}$. La resistencia de los agrarios contribuyó a

41 La denuncia de Prieto en $D S C-C D, 7-4-1921$, pp. 1.154s.

42 Las críticas de los agricultores al proyecto de reforma arancelaria auspiciado por Cambó en El Progreso Agrícola y Pecuario, 7-1-1922, p. 1.

43 El proyecto para prohibir la importación de trigo fue leído por Cambó en el Congreso el 8 de noviembre de 1921, DSC-CD , 8-11-1921, apéndice primero. Entró en vigor, sin haber superado la discusión parlamentaria, gracias a que fue publicado como decreto en la Gaceta de Madrid, 9-11-1921, p. 453.

44 La protesta de la Asociación de Agricultores de España en El Progreso Agrícola y Pecuario, 7-3-1921, p. 130. 
minar la posición de un gobierno muy debilitado por la cuestión marroquí y por las divisiones internas ${ }^{45}$.

El nuevo gobierno presidido por el conservador Sánchez Guerra desde el 8 de marzo de 1922, con Manuel Argüelles Argüelles en Fomento y Francisco Bergamín en Hacienda, se mostró más receptivo a introducir modificaciones arancelarias de acuerdo con las demandas de los diputados agrarios ${ }^{46}$. En primer lugar, presentó el proyecto de prohibición de importar trigo redactado por Cambó para su discusión en el Congreso, pero, a continuación, aceptó dos enmiendas, que modificaron su contenido de forma sensible, inspiradas en los intereses de los grupos agrarios.

Por un lado, el Gobierno aceptó la enmienda de los diputados agrarios que pretendía mantener de forma indefinida la prohibición de importar trigo mientras no se superase un determinado precio regulador en los mercados de Castilla, como se aprobó en 1820. Con esta propuesta se pretendía consolidar la prohibición en función de los precios del mercado, y no de la valoración de la coyuntura que los gobiernos pudieran efectuar en cada momento. Por otro lado, también se aprobó el voto particular de los diputados gallegos para admitir la importación de maíz con un bajo arancel por las provincias gallegas ${ }^{47}$. Eran dos propuestas contradictorias, ya que aumentaban la protección para el trigo pero la disminuían para el maíz, aunque sólo en Galicia, pero esta suma de intereses garantizó la mayoría parlamentaria necesaria para aprobar el proyecto de ley ${ }^{48}$.

A los diputados agrarios no les gustaba la reducción arancelaria sobre el maíz importado, ya que acabaría incidiendo en los precios del resto de los cereales, pero terminaron por aceptarla ante las reclamaciones de los ganaderos gallegos y después de vincular la prohibición de importar trigo a un precio regulador. De esta manera, la oposición a esta medida fue minoritaria y se concentró en los representantes de las ciudades del litoral deficitario. De nuevo el socialista Prieto criticó abiertamente el proyecto. Lo calificó de "funesto" porque contribuiría a aumentar los precios de los productos básicos y no solucionaría el problema de una agricultura "deficientísima". Al mismo tiempo, Prieto también censuró la reforma arancelaria de Cambó porque un sistema tan proteccionista acabaría por "ahogar todo" 49 .

Asimismo, Cambó, como representante de una Barcelona netamente importadora de trigo, también se opuso a las enmiendas introducidas en su originario proyecto de prohibición. Criticó abiertamente que la prohibición se ligara a un precio interior muy elevado, sin relación con el precio de coste, y que recargaría el precio del pan de

45 La caída de Cambó en marzo de 1922 fue un alivio para los grupos de presión agrícola, en El Progreso Agrícola y Pecuario, 15-3-1921, p. 147.

46 Bergamín anunció su propósito de modificar el proyecto de Cambó de acuerdo con las demandas de los diputados agrarios: aumentar el arancel sobre el trigo a 14 pesetas el quintal métrico, mantener la prohibición de importar para el trigo, rebajar el arancel al carbón y prometió negociar tratados comerciales por debajo de la segunda columna para favorecer la salida de las exportaciones agrícolas. La favorable acogida de los grupos agrarios a esta rectificación gubernamental en El Progreso Agrícola y Pecuario, 31-3-1921, p. 186. 47 El dictamen de la Comisión permanente de Hacienda sobre el proyecto de ley prohibiendo la introducción en España de trigos y harinas procedentes del extranjero en $D S C$-CD, 30-3-1922, apéndice $8^{\circ}$. La enmienda de los diputados agrarios (Gasset, Crespo de Lara, Cánovas del Castillo, Gascón y Marín, etc.) en DSC-CD, 30-3-1922, apéndice $2^{\circ}$. El voto particular de los diputados gallegos en $D S C$ - $C D, 31-3-1922$, apéndice $1^{\circ}$.

$48 \mathrm{El}$ diputado agrario Mariano Matesanz advirtió de forma clara que sin un reforzamiento de la protección triguera no hubieran consentido la aprobación de la reforma arancelaria impulsada por Cambó, que consideraban muy beneficiosa para la industria, $D S C-C D$, 23-5-1922, p. 1.696.

49 Prieto llegó a decir en el Congreso que con estas medidas algunos españoles tendrían que "comer hierba", $D S C-C D, 7-4-1922$, p. 749 y 752. 
una forma considerable para las clases populares del litoral. Además, como el precio regulador era demasiado alto, el hambre y las protestas sociales estallarían en el litoral mediterráneo mucho antes de alcanzarse ese precio en el mercado de Valladolid. Por lo tanto, era un grave error que el Gobierno perdiera su capacidad para intervenir en los momentos de crisis de escasez, que careciera de libertad para levantar la prohibición y evitar problemas de orden público ${ }^{50}$.

Precisamente, era esa discrecionalidad gubernamental la que los diputados agrarios pretendían eliminar. Su desconfianza nació de la actuación de Cambó en su etapa ministerial. El diputado albista y propietario Matesanz replicó a las críticas de Cambó con una denuncia de su contradictorio comportamiento: al mismo tiempo que decretó la prohibición de importar trigo, "para comprar su silencio", concedió numerosas autorizaciones para importar trigo que beneficiaron a las harineras catalanas y que terminaron por paralizar la venta de trigos castellanos. Para los diputados agrarios ese tipo de prohibición era un timo ya que el Gobierno podía suspenderla ante cualquier circunstancia, como los frecuentes conflictos sociales en Barcelona. Otro de los líderes agrarios, Cánovas del Castillo, exigió una protección real si se quería evitar la ruina de los agricultores y la despoblación de Castilla y afirmó que el precio regulador fijado, 53 pesetas por cien kilos, apenas cubría el precio de coste y resultaba imprescindible para que los trigos del interior pudieran venderse en el litoral ${ }^{51}$. Este había sido el objetivo de los grupos de presión agrarios desde el comienzo de su campaña y de ahí su cerrada oposición a la gestión de Cambó. Con el gobierno Sánchez Guerra, aunque tuvieron que ceder en la cuestión del maíz, consiguieron lo que consideraban una protección suficiente ${ }^{52}$.

\section{EL PROHIBICIONISMO TRIGUERO: DISCURSOS Y EVIDENCIAS}

La reivindicación prohibicionista de los agricultores se apoyó en el deterioro de la balanza comercial española y en la reacción nacionalista generalizada en el periodo de posguerra. Tras los superávit de los periodos 1909-1913 y 1914-1919, el importante déficit comercial acumulado desde 1920 favoreció la difusión de las alternativas más proteccionistas. El alto nivel de protección del arancel Cambó de $1922^{53}$ estimuló a los agricultores a exigir un reforzamiento de las barreras comerciales para el trigo. Esta tendencia también se fortaleció por la extensión de tendencias aislacionistas en el comercio internacional. Pero es necesario contrastar el dramático discurso de los agricultores con las realidades económicas y comprobar hasta qué punto se produjo un rápido deterioro de la posición del sector.

50 La intervención de Cambó en DSC-CD, 17-5-1922, pp. 1.616-1.619.

$51 \mathrm{La}$ intervención de Matesanz en $D S C-C D, 23-5-1922$, pp. 1.696-1.703. Señaló que durante el primer trimestre de la prohibición entraron en España 974.000 quintales de trigo, p. 1.708. La de Cánovas del Castillo, DSC-CD, 30-5-1922, pp. 1.938-1.940.

52 El ministro de Hacienda Bergamín no sólo vinculó la prohibición de importar trigo a un precio regulador, también recogió en la Ley de Autorizaciones de abril de 1922 la posibilidad de negociar rebajas arancelarias en la segunda columna para favorecer las exportaciones agrícolas. La satisfacción de los agricultores con las modificaciones arancelarias de Bergamín en El Progreso Agrícola y Pecuario, 22-5-1922, p. 294.

53 Las revisiones arancelarias de este periodo en SERRANO SANZ, José María: "Proteccionismo, Arancel Cambó y Tratados Comerciales. La política arancelaria española al término de la Primera Guerra Mundial", en José Luis García Delgado (ed.): La crisis de la Restauración. España entre la Primera Guerra Mundial y la II República, Madrid, Siglo XXI, 1986, pp. 199-223. 
$\mathrm{Si}$ analizamos los precios constantes del trigo en las zonas de producción excedentaria, tomando como base el quinquenio anterior a la guerra y descontando el efecto de la inflación ${ }^{54}$, se confirma que desde 1922 los precios se situaron por debajo del nivel del periodo prebélico. Pero a pesar de esa contracción, los precios no fueron inferiores a lo que los intereses agrícolas denominaron precio remunerador antes de 1914. Ya se ha indicado que ese precio remunerador se fijó a partir de explotaciones tradicionales y con rendimientos muy pobres. En consecuencia, fueron este tipo de explotaciones las que sufrieron en mayor medida con la normalización de los mercados internacionales del trigo. Las mismas que ya antes del conflicto bélico debían afrontar una reorganización de su actividad productiva. Sin embargo, la superficie sembrada no se redujo sino que siguió aumentando durante la guerra.

Los grupos agrícolas no tomaron como única referencia la situación anterior a 1914. La demanda prohibicionista pretendía aislar al mercado español de la normalización de los mercados internacionales para tratar de mantener los beneficios extraordinarios del periodo bélico. Para ellos no fue suficiente la vuelta a un alto arancel fijo como se contempló en el arancel de 1922: las diez pesetas por quintal métrico suponían una protección efectiva del $35 \%$ sobre los precios internacionales, similar a la existente antes de la guerra. La demanda de prohibición aspiraba a mantener una posición adquirida en una coyuntura extraordinaria. Al adoptar un precio regulador de 53 pesetas el quintal métrico, uno de los más elevados del periodo, se aseguró el mercado del litoral para las zonas excedentarias del interior. Ese precio regulador, en precios constantes, era equivalente a 29 pesetas el quintal métrico. Un precio hasta un quince por ciento más elevado que el precio remunerador defendido antes de 1914. De esta manera, se aseguraba la supervivencia de las explotaciones tradicionales, se dificultaba la reducción de la superficie sembrada, y se intentaba frenar la caída de la renta de la tierra.

Las demandas proteccionistas de la burguesía industrial del litoral tras el fin de la primera guerra mundial, y que fueron asumidas en la reforma arancelaria promovida por Cambó, revitalizaron la movilización de los grupos de presión agrícola. Éstos reclamaron un nuevo pacto arancelario que, finalmente, incluyó la prohibición de importar trigo. Pero este retorno del prohibicionismo fomentó tendencias autárquicas que terminaron por perjudicar a los centros urbanos del litoral, zonas de importantes concentraciones obreras y de intensa conflictividad social, debido al encarecimiento de un producto básico como el trigo.

La crisis del régimen político de la Restauración derivó en un recorte progresivo de los derechos políticos que, finalmente, se consolidó con el triunfo del golpe militar de 1923. La prohibición de importaciones para el trigo se dio también en un contexto político regresivo, con graves limitaciones sobre las libertades públicas, con la prohibición o limitación de las organizaciones sindicales y con el retroceso forzoso de la negociación colectiva ${ }^{55}$. En este contexto, a pesar de que en 1924 la cosecha fue muy pobre y las reservas se redujeron, las importaciones no se autorizaron y los precios del

54 He tomado como referencia el deflactor calculado por PRADOS DE LA ESCOSURA, Leandro: op. cit., p. 364.

55 La creciente influencia de las organizaciones patronales en la elaboración de la política económica tras la primera guerra mundial en BERGER, Suzanne. (Comp.): La organización de los grupos de interés en Europa Occidental. El pluralismo, el corporativismo y la transformación de la política, Madrid, 1988. En España en REY REGUILLO, Fernando, op. cit., y MARTORELL, Miguel, op. cit. 
trigo volvieron a subir, mientras la conflictividad social, urbana y jornalera, retrocedió drásticamente por la represión de las organizaciones sindicales. Los precios del trigo en Valladolid y en Barcelona llegaron a los mismos niveles de 1918, mientras que en el mercado internacional siguieron descendiendo. El promedio anual del precio del trigo en Barcelona llegó a superar el precio regulador de 53 pesetas el quintal métrico, pero no se autorizaron las importaciones. El precio de Barcelona fue superior en un $69 \%$ al alcanzado en Inglaterra. En consecuencia, en 1924 la transferencia de renta a favor de los sectores agrícolas fue considerable: fue equivalente al $2 \%$ del producto interior bruto ${ }^{56}$.

En conclusión, el establecimiento de la prohibición de importar trigo resultó ser una medida defensiva muy desproporcionada en aquel momento, que llegó a suponer el establecimiento de una protección superior a la existente antes de $1914^{57}$ y que, sobre todo, benefició a las zonas excedentarias que habían seguido incrementado la superficie cultivable durante el conflicto bélico y a los derechos de propiedad establecidos.

APÉNDICE I. EL MERCADO DEL TRIGO

El mercado del trigo en España, 1909-1913 (promedios anuales)

\begin{tabular}{lcccc}
\hline \multicolumn{1}{c}{ Regiones } & Producción $($ Qm.) & $\begin{array}{c}\text { Superficie } \\
(\text { Has. })\end{array}$ & $\begin{array}{c}\text { Productividad } \\
(\text { Qm/ha })\end{array}$ & $\begin{array}{c}\text { Producción- } \\
\text { Consumo } \\
(\text { Qm. })\end{array}$ \\
\hline Castilla, León, Álava & 14.784 .961 & 1.844 .781 & 8 & 4.670 .629 \\
Ebro & 5.835 .833 & 515.176 & 11 & 2.423 .626 \\
Sur interior & 8.300 .360 & 804.788 & 10 & 2.313 .490 \\
Litoral andaluz & 2.132 .248 & 232.698 & 9 & -810.918 \\
Litoral mediterráneo & 3.478 .081 & 337.224 & 10 & -4.336 .181 \\
Litoral norte & 894.098 & 78.931 & 11 & -4.873 .370 \\
Total & 35.425 .580 & 3.813 .599 & 9 & -612.724 \\
\hline
\end{tabular}

El mercado del trigo en España, 1919-1921 (promedios anuales)

\begin{tabular}{lcccc}
\hline \multicolumn{1}{c}{ Regiones } & Producción $($ Qm.) & $\begin{array}{c}\text { Superficie } \\
\text { (Has.) }\end{array}$ & $\begin{array}{c}\text { Productividad } \\
(\text { Qm/ha })\end{array}$ & $\begin{array}{c}\text { Producción- } \\
\text { Consumo } \\
(\text { Qm. })\end{array}$ \\
\hline Castilla, León y Álava & 16.967 .862 & 2.051 .362 & 8 & 6.240 .325 \\
Ebro & 7.565 .843 & 609.282 & 12 & 3.912 .361 \\
Sur interior & 6.414 .209 & 791.120 & 8 & -47.384 \\
Litoral andaluz & 1.663 .185 & 240.395 & 7 & -1.444 .572 \\
Litoral mediterráneo & 3.481 .483 & 356712 & 10 & -4.386 .057 \\
Litoral norte & 1.128 .713 & 81.383 & 14 & -5.001 .500 \\
Total & 37.221 .296 & 4.130 .254 & 9 & -726.828 \\
\hline
\end{tabular}

56 La diferencia entre el valor de la producción triguera española, tomando los precios de Valladolid, y el valor de esa misma producción, tomando los precios de Inglaterra, superó los 596 millones de pesetas. Esta cantidad representaba el $2 \%$ del producto interior bruto al coste de los factores calculado por Prados de la Escosura para 1924, PRADOS DE LA ESCOSURA, Leandro: op. cit., p. 283.

$57 \mathrm{El}$ coeficiente de protección nominal (precios de Barcelona/precios ingleses) pasó de 1,5 para el periodo $1909-1913$ a 1,7 en 1924. 
Fuentes y elaboración. Las cifras de producción y de superficie sembrada en G. E. H. R.: Estadísticas históricas de la producción agraria española, 1859-1935, Madrid, 1991. La composición provincial de las regiones es la siguiente: Castilla y León (Madrid, Albacete, Ciudad Real, Toledo, Guadalajara, Cuenca, Valladolid, Burgos, Ávila, Segovia, Soria, Palencia, Salamanca, León, y Zamora) y Álava; Ebro (Logroño, Navarra, Zaragoza, Huesca, Teruel, Lérida); Sur interior (Jaén, Granada, Sevilla, Córdoba, Badajoz, Cáceres); Litoral andaluz (Málaga, Almería, Huelva, Cádiz); Litoral mediterráneo (Barcelona, Tarragona, Gerona, Baleares, Valencia, Castellón, Alicante, Murcia); Litoral norte (Coruña, Lugo, Orense, Pontevedra, Guipúzcoa, Vizcaya, Santander, Oviedo). Para establecer el consumo de trigo se ha tenido en cuenta, en primer lugar, la cantidad empleada en la siembra. Se ha multiplicado la superficie sembrada en cada periodo por 1,3, ya que los datos recogidos en el Anuario Estadístico de España permiten establecer un promedio de 1,3 quintales métricos por hectárea utilizados en la siembra en los periodos seleccionados. Para establecer el consumo humano se han tomado los datos de los censos de población de 1910 y de 1920 y se han multiplicado por 1, 56 quintales métricos, que es la cifra que recomienda MONTOJO SUREDA, Jorge: op. cit., p. 101 como promedio del consumo por habitante a lo largo de todo el periodo. Esta cifra resulta algo menor que el trigo disponible por habitante calculado a partir de las cifras anuales de producción, consumo e importaciones de trigo entre 1909 y 1935: con los datos del Anuario Estadístico de España se obtiene una cifra de 1,67 quintales métricos por habitante entre 1906 y 1920 , y de 1,61 entre 1921 y 1935. El promedio más alto en la primera etapa se debió sobre todo al incremento de las existencias durante la primera guerra mundial ante las dificultades de los mercados internacionales. Por consiguiente, estas cifras parecen indicar que no existió un cambio importante en la pauta de consumo a lo largo del periodo y permiten emplear una cantidad constante para estimar el consumo global por habitante.

\section{APÉNDICE II}

Existencias en el mercado español (qm.) y precios del trigo (ptas./qm).

\begin{tabular}{ccccccc}
\hline & Producción & Importación & Existencias & Valladolid & Barcelona & Inglaterra \\
\hline $1909-1913$ & 35.501 .966 & 1.202 .692 & 324.086 & 27 & 33 & 20 \\
1914 & 31.594 .489 & 4.226 .134 & -1.515 .067 & 31 & 35 & 21 \\
1915 & 39.233 .823 & 3.714 .254 & 5.207 .851 & 35 & 39 & 32 \\
1916 & 41.457 .516 & 3.149 .069 & 6.564 .017 & 38 & 42 & 35 \\
1917 & 38.830 .020 & 505.699 & 986.745 & 42 & 47 & 45 \\
1918 & 36.934 .000 & 652.000 & -926.951 & 50 & 54 & 44 \\
1919 & 35.176 .000 & 3.364 .000 & -311.061 & 52 & 55 & 44 \\
1920 & 37.722 .000 & 4.814 .000 & 3.580 .314 & 66 & 74 & 42 \\
1921 & 39.504 .000 & 5.251 .000 & 5.446 .214 & 53 & 53 & 45 \\
1922 & 34.147 .000 & 2.249 .000 & -3.041 .340 & 45 & 45 & 30 \\
1923 & 42.759 .000 & & 2.990 .363 & 46 & 48 & 36 \\
1924 & 33.143 .000 & & -6.799 .919 & 50 & 54 & 32 \\
\hline
\end{tabular}

Fuente: Estimación propia a partir de los Anuarios Estadísticos de España, Garrabou, Tello y Roca (1999), Mitchell y Deane (1962).

Los datos de producción, precios de Valladolid e importaciones anuales proceden de los Anuarios Estadísticos de España. Los precios de Barcelona proceden de GARRABOU, Ramón; TELLO, Enrique y ROCA, Albert: "Preus del Blat i salaris agrícolas a Catalunya (1720-1936)", en La industrialización y el desarrollo económico de España. Homenaje al doctor Jordi Nadal, Barcelona, v. I, 1999, pp. 422-460. Los precios de Inglaterra son de MITCHELL, Brian y DEANE, Phyllis: Abstract of British Historical Statistics, Cambridge, Cambridge University Press, 1962. Las existencias se han calculado a partir de los datos de producción, comercio exterior y consumo de trigo (siembras y consumo humano, a partir de las cifras indicadas en el apéndice I). La conversión de los precios ingleses a pesetas se ha realizado teniendo en cuenta el tipo de cambio anual. 